Annals of International Medical and Dental Research

E-ISSN: 2395-2822 | P-ISSN: 2395-2814

Vol-8, Issue-1 | January-February 2022

DOI: 10.53339/aimdr.2022.8.1.3

Page no- 12-23 | Section- Research Article (Radiodiagnosis)

\title{
Imaging Findings of Knee Trauma on Magnetic Resonance Imaging
}

\section{Poonam Ohri', Shreeji Goyal2*, Niveditha ${ }^{3}$, Manasi Kohli ${ }^{4}$}

\begin{abstract}
${ }^{1}$ Associate Professor, Department of Radiodiagnosis, Goverment Medical College, Amritsar, Punjab, India.

Email: drohripoonam@gmail.com

Orcid ID: 0000-0003-3413-4915

${ }^{2}$ Assistant Professor, Department of Obstetrics and Gynaecology, Goverment Medical College, Amritsar, Punjab, India. Email: shreejigoyal@gmail.com

Orcid ID: 0000-0001-6500-8001

3Senior Resident, Department of Radiodiagnosis, Goverment Medical College, Amritsar, Punjab, India.

Email:niveditha.b91@gmail.com

Ordid ID: 0000-0001-7152-5814

${ }^{4}$ Intern, SGRR Medical College,

Dehradun, Uttarakhand, India.

Email:themanasikohli@gmail.com

Orcid ID: 0000-0002-0793-0601

*Corresponding author
\end{abstract}

Received: 05 September 2021

Revised: 18 October 2021

Accepted: 27 October 2021

Published: 22 December 2021

\section{Abstract}

Background: Knee is one of the major joints involved in kinesis. With increasing involvement in sports related activities especially in young people, Trauma related knee pathologies have increased. An accurate diagnosis regarding the type and extent of injuries is essential for early operative as well as non-operative treatment. Methods: This prospective study included total of 82 cases. The patients were referred to the department of Radiodiagnosis from indoor and outdoor departments of Guru Nanak Dev Hospital, Amritsar with suspicion of internal derangement of the knee and with history of knee trauma. Results: The most common age group involved was young males between 15-34 years. In all age groups most of the patients were males. Most common ligament to be injured was Anterior Cruciate Ligament (ACL). Partial tears were more common than complete tears. Posterior Cruciate Ligament (PCL) tears were less common. Medial Collateral Ligament (MCL) tears outnumbered Lateral Collateral Ligament (LCL) tears and grade 2 tears were more common in both. Among the meniscal injuries Medial Meniscus (MM) tears were more common than LM and grade 3 signal was more common in both. Most of the patellar retinaculum injuries were associated with Anterior Cruciate Ligament ACL tears. Conclusions: Post-traumatic pre-arthroscopic MR imaging evaluation has proved to be cost-effective. MRI is an accurate imaging modality complementing the clinical evaluation and providing a global intra-articular and extra-articular assessment of the knee.

Keywords:- Knee, Trauma, Anterior Cruciate Ligament, Posterior Cruciate Ligament, Medial Collateral Ligament, Lateral Collateral Ligament, Meniscus.

\section{INTRODUCTION}

Knee is one of the major joints involved in kinesis, so also bears the consequences of increased mobility i.e. tendency to instability. With increasing involvement in sports related activities especially in young people, trauma related knee pathologies have increased. An accurate diagnosis regarding the type and extent of injuries is essential for early operative as well as non-operative treatment.
The most widely used diagnostic modalities to assess joint injury are arthroscopy and Magnetic Resonance Imaging [MRI]. Arthroscopy, though accurate, is invasive and can cause complications. ${ }^{1,2]}$ It has been reported to have a high diagnostic accuracy and does not involve the use of ionizing radiation. [3] It has also allowed to avoid the morbidity due to invasive procedures.[4] 
Annals of International Medical and Dental Research

E-ISSN: 2395-2822 | P-ISSN: 2395-2814

Vol-8, Issue-1 | January-February 2022

DOI: $10.53339 /$ aimdr.2022.8.1.3

Page no- 12-23 | Section- Research Article (Radiodiagnosis)

Three-dimensional MRI currently provides comparable diagnostic performance to twodimensional MRI for depicting knee meniscal injuries irrespective of the magnetic field of imagers. [5]

The knee joint is a compound type of synovial joint and due to the lack of bony support, stability of the joint is highly dependent on its supporting ligamentous structures, therefore injuries of ligaments and menisci are extremely common. $[6,7]$

This study was undertaken to evaluate the types and incidence of knee joint injuries by MRI.

\section{$\underline{\text { Aims and Objectives }}$}

1. Study of MRI patterns of ligamentous, meniscal tears and osseous injuries.

2. Grading of various ligamentous and meniscal tears on the basis of laid down criteria.

\section{MATERIAL AND METHODS}

This prospective study included total of 82 cases. The patients were referred to the department of Radiodiagnosis from indoor and outdoor departments of Guru Nanak Dev Hospital, Amritsar with suspicion of internal derangement of the knee and with history of knee trauma.

\section{Imaging techniques}

Patients of all the ages and both the sexes having history of knee injury referred from Orthopaedics departments were enrolled in the study after obtaining their written and informed consent. The demographic features and clinical history of each patient included in the study was noted down in a predesigned prescribed questionnaire and any contraindication to MRI was assessed including cochlear implants, surgical metallic clips, cardiac pacemaker or any metallic foreign body. Hence such patients were excluded. Before the procedure, patients or relatives were explained about the procedure. In case of unconscious or minor patient, consent was taken from the relatives or guardian.

\section{Equipment used}

Patients were examined using one with the SIEMENS MAGNETOM AERA 1.5 TESLA MRI. MRI films and CDs or DVDs were used for recording the images.

\section{Positioning and Coil Selection}

Patient is placed in supine position with the knee in a large flex coil. The knee is externally rotated $15-20^{\circ}$, in order to facilitate the visualisation of ACL completely on sagittal images. The knee is flexed slightly $5-10^{\circ}$, to increase the accuracy of assessing the patellofemoral compartment and patellar alignment.

\section{Pulse Sequences and Imaging Planes}

i. Fat saturated PD weighted sequences in sagittal, axial and coronal planes.

ii. T2- weighted sequence in sagittal plane. iii.T1-weighted sequence in coronal plane.

(Sometimes GRE sequence in axial plane and $3 \mathrm{D} P D$ sequence in sagittal image to supplement the information obtained from routine set of sequences).

We examined the knee in these three planes using a FOV of $16 \times 16 \mathrm{~cm}, 256$ X 256 matrix, \& 3 $\mathrm{mm}$ slice thickness. Average time taken to complete a scan was 16 minutes 17 seconds. An 
Annals of International Medical and Dental Research E-ISSN: 2395-2822 | P-ISSN: 2395-2814 Vol-8, Issue-1 | January-February 2022 DOI: 10.53339/aimdr.2022.8.1.3 Page no- 12-23 | Section- Research Article (Radiodiagnosis)

axial acquisition through patellofemoral joint was used as initial localizer for subsequent sagittal and coronal plane images. The coronal plane optimally evaluated the collateral ligaments and body of the menisci. The sagittal plane revealed the cruciate ligaments, menisci and synovial anatomy especially the suprapatellar pouch. Overall bones, muscles, tendons and neurovascular structures were fully evaluated with integration of all three planes.

\section{RESULTS}

A descriptive statistical analysis and correlation evaluation study consisting of 82 patients with traumatic knee joint was undertaken to study the spectrum of MRI findings in all consecutive cases of knee trauma referred from orthopaedic OPD, and comparison of findings of magnetic resonance imaging with arthroscopic findings in selected cases.
15-24 age group comprised the maximum number of cases $(34.2 \%)$ followed by $30.5 \%$, $18.3 \%, 13.4 \%$ and $3.6 \%$ in the age group of 25 $34,35-44,45-54$ and 55-64 respectively. In all age groups most of the patients were males. In age group 55-64, only males were seen 67 $(81.7 \%)$ patients were males as compare to 15 $(17.3 \%)$ females.

Right knee was involved in $39(47.6 \%)$ cases whereas left in $43(52.4 \%)$ cases [Table 3]. 27 $(33 \%)$ cases presented between 1-2 months of injury followed by $22(26.8 \%), 12(14.6 \%), 10$ $(12.2 \%), 8(9.8 \%)$ \& 3 (3.6\%) in 2-3months, $4-6$ months, 3-4 months, upto 1 month and after 6 months respectively.

The most common presenting symptom was pain in $73(87.8 \%)$ patients while the second most common symptom seen was swelling in $45 \quad(54.8 \%)$ patients. Other presenting symptoms were joint stiffness in $6(7.3 \%)$, locking of joint in 3 (3.6\%) and feeling of giving away in $7(8.5 \%)$ patients respectively.

Table 1: Anterior Cruciate Ligament injury

\begin{tabular}{|l|l|l|}
\hline $\begin{array}{l}\text { Anterior Cruciate Ligament injury } \\
\text { with grade }\end{array}$ & Frequency & Percentage \\
\hline Normal & 28 & 34.2 \\
\hline Grade 1 (Sprain) & 3 & 5.5 \\
\hline Grade 2 (Partial tear) & 35 & 64.8 \\
\hline Grade 3 (Complete tear) & 16 & 19.5 \\
\hline
\end{tabular}

Table 2: Posterior Cruciate Ligament injury

\begin{tabular}{|l|l|l|}
\hline Posterior Cruciate Ligament injury with grade & Frequency & Percentage \\
\hline Normal & 70 & 85.4 \\
\hline Grade 1 (Sprain) & 1 & 1.2 \\
\hline Grade 2 (Partial tear) & 5 & 6.1 \\
\hline Grade 3 (Complete tear) & 6 & 7.3 \\
\hline
\end{tabular}




\section{Anterior Cruciate Ligament injury}

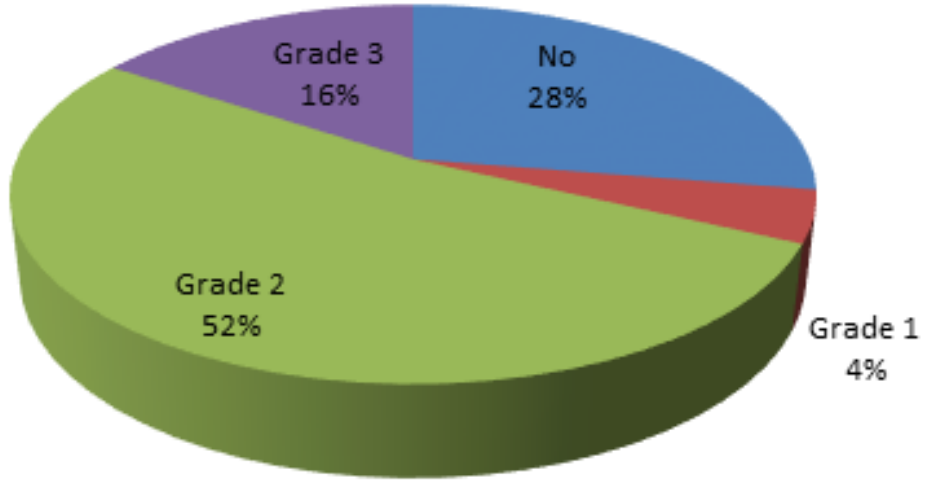

Figure 1: Percentage wise distribution of Anterior Cruciate Ligament injury.

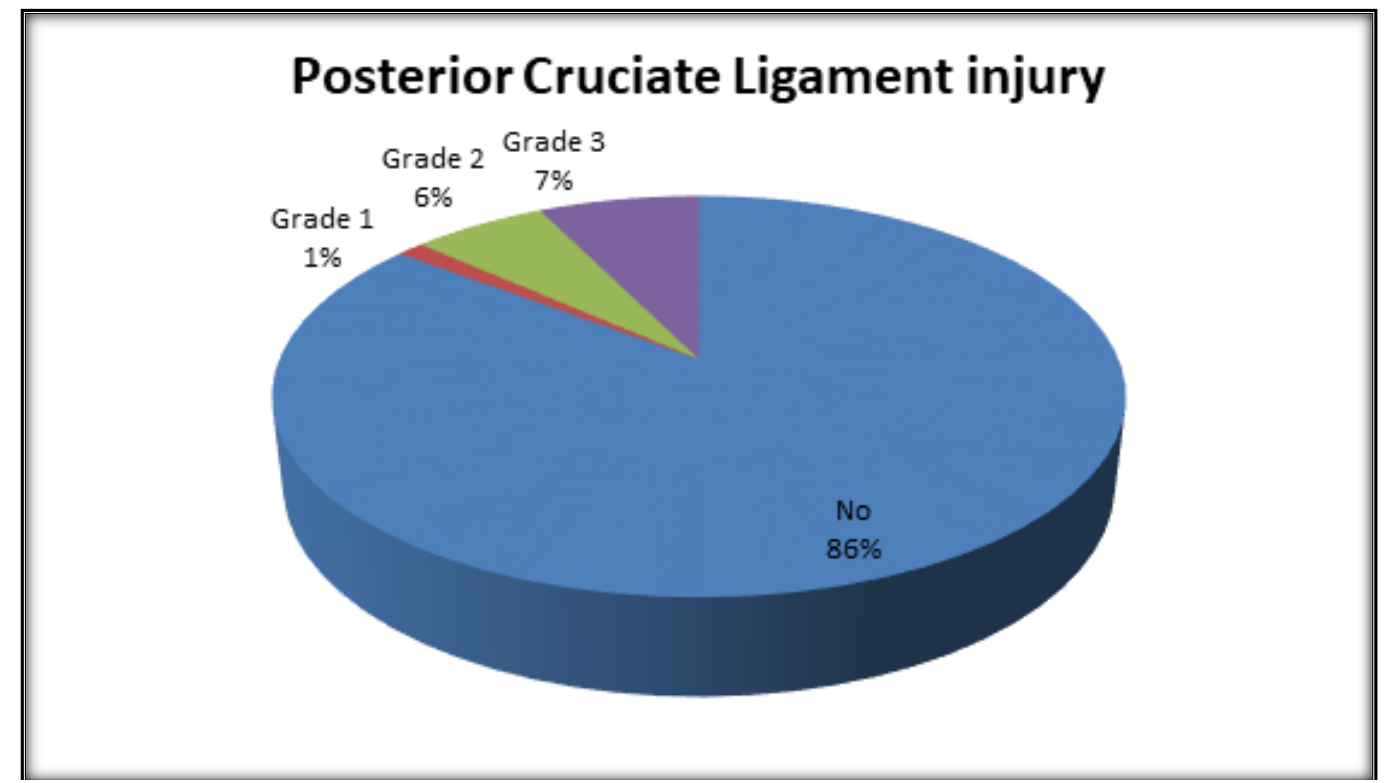

Figure 2: Percentage wise distribution of Posterior Cruciate Ligament injury

Table 3: Medial Collateral Ligament injury

\begin{tabular}{|l|l|l|}
\hline Medial Collateral Ligament injury with grade & Frequency & Percentage \\
\hline Normal & 65 & 79.3 \\
\hline Grade 1 (Sprain) & 4 & 4.9 \\
\hline Grade 2 (Partial tear) & 12 & 14.6 \\
\hline Grade 3 (Complete tear) & 1 & 1.2 \\
\hline
\end{tabular}




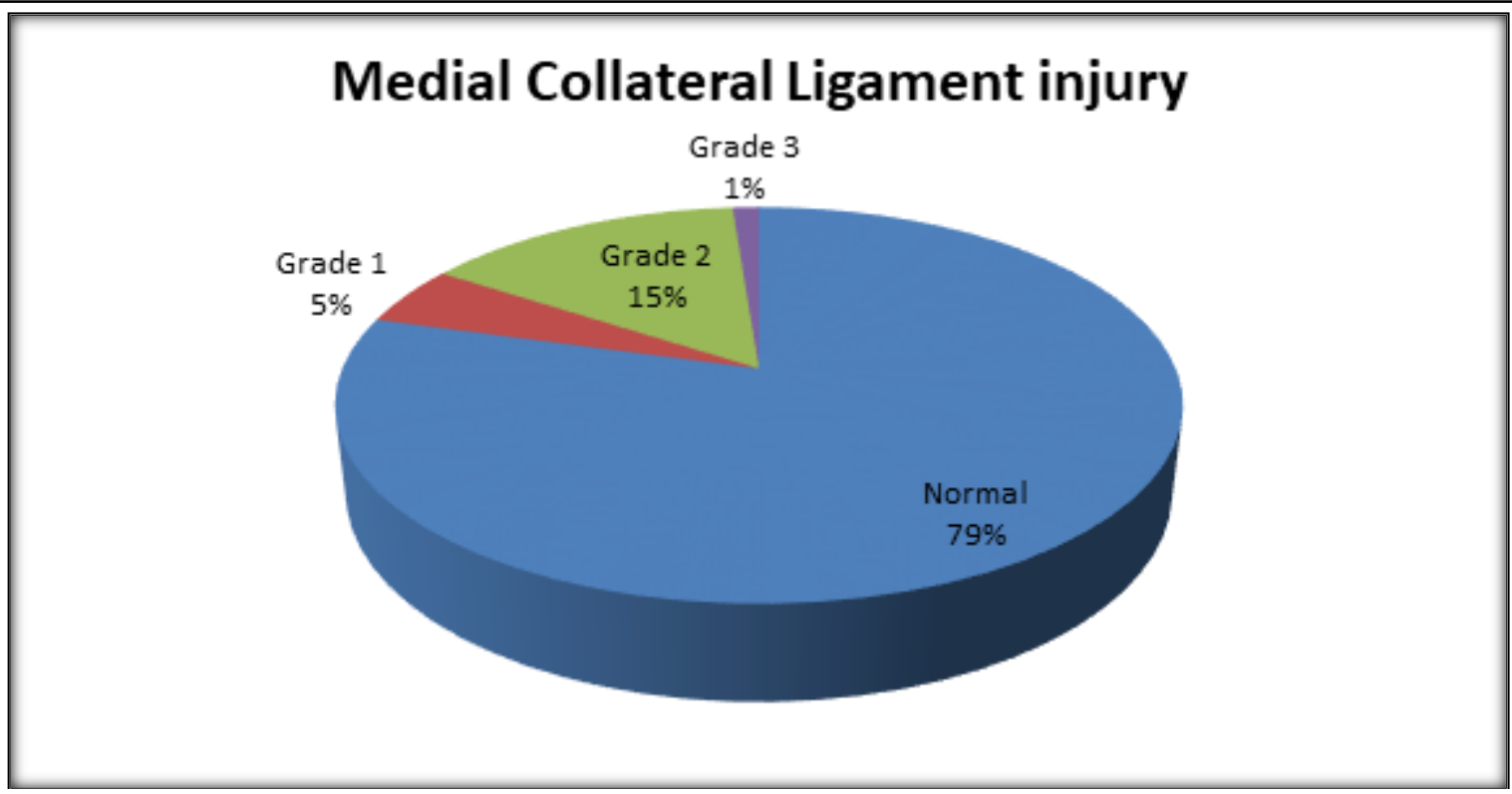

Figure 3: Percentage wise distribution of Medial Collateral Ligament injury.

Table 4: Lateral Collateral Ligament injury

\begin{tabular}{|l|l|l|}
\hline Lateral Collateral Ligament injury with grade & Frequency & Percentage \\
\hline Normal & 77 & 93.9 \\
\hline Grade 1 (Sprain) & 0 & 0 \\
\hline Grade 2 (Partial tear) & 5 & 6.1 \\
\hline Grade 3 (Complete tear) & 0 & 0 \\
\hline
\end{tabular}

\section{Lateral Collateral Ligament injury}

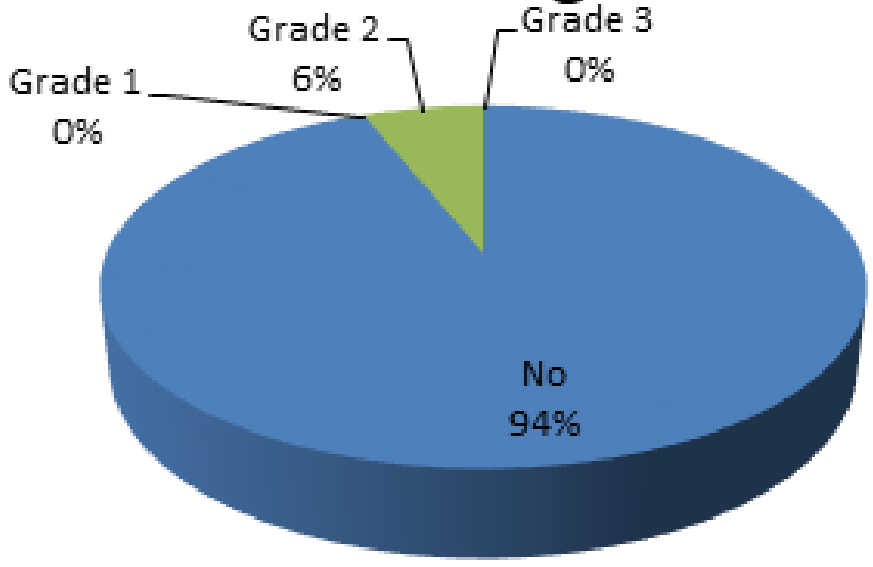

Figure 4: Percentage wise distribution of Lateral Collateral Ligament injury. 
Annals of International Medical and Dental Research

E-ISSN: 2395-2822 | P-ISSN: 2395-2814

Vol-8, Issue-1 | January-February 2022

DOI: 10.53339/aimdr.2022.8.1.3

Page no- 12-23 | Section- Research Article (Radiodiagnosis)

Table 5: Medial meniscal injury

\begin{tabular}{|l|l|l|}
\hline Medial meniscal signal grade & Frequency & Percentage \\
\hline Normal & 44 & 53.7 \\
\hline Grade 1 & 7 & 8.5 \\
\hline Grade 2 & 6 & 7.3 \\
\hline Grade 3 (Tear) & 25 & 30.5 \\
\hline
\end{tabular}

\section{Medial meniscal injury}

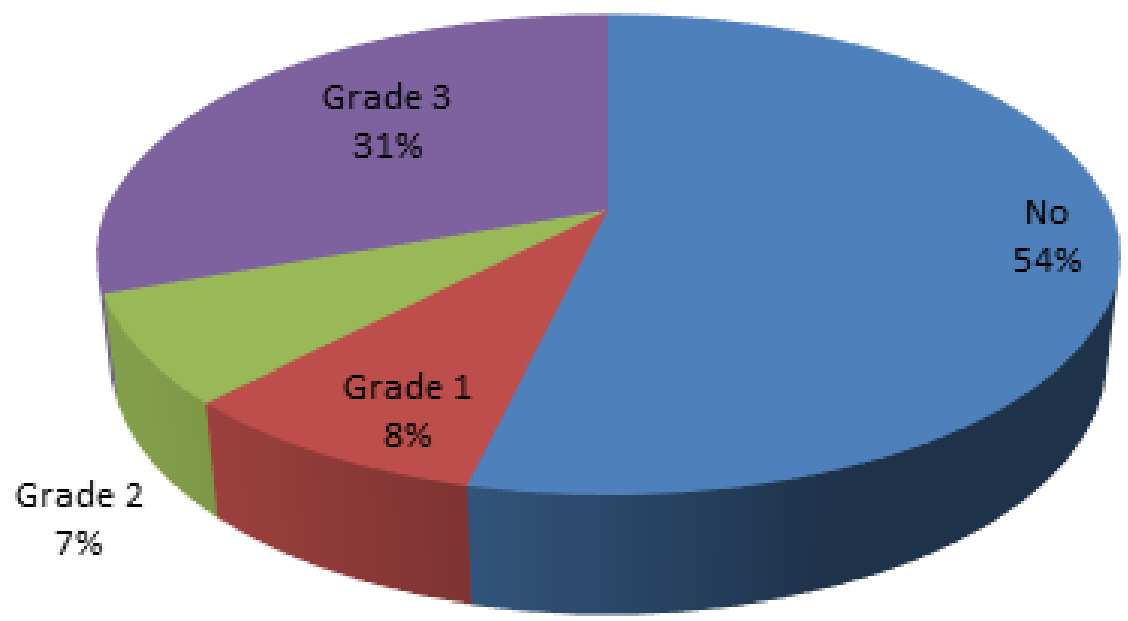

Figure 5: Percentage wise distribution of Medial meniscal injury.

Table 6: Lateral meniscal injury

\begin{tabular}{|l|l|l|}
\hline Lateral meniscal signal grade & Frequency & Percentage \\
\hline Normal & 51 & 62.2 \\
\hline Grade 1 & 7 & 8.5 \\
\hline Grade 2 & 4 & 4.9 \\
\hline Grade 3 (Tear) & 20 & 24.4 \\
\hline
\end{tabular}

Table 7: Patellar retinaculum injury

\begin{tabular}{|l|l|l|}
\hline Patellar retinaculum injury & Frequency & Percentage \\
\hline Normal & 60 & 73.1 \\
\hline Medial Patellar Retinaculum (MPR) & 17 & 20.7 \\
\hline Lateral Patellar Retinaculum (LPR) & 7 & 8.5 \\
\hline
\end{tabular}




\section{LM injury}

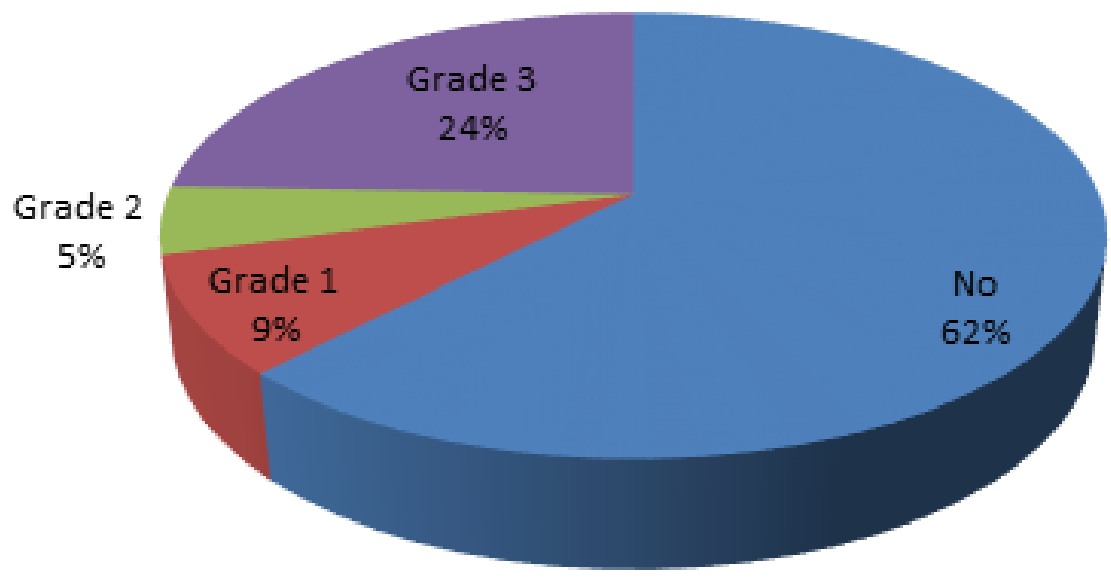

Figure 6: Percentage wise distribution of Lateral meniscal injury.

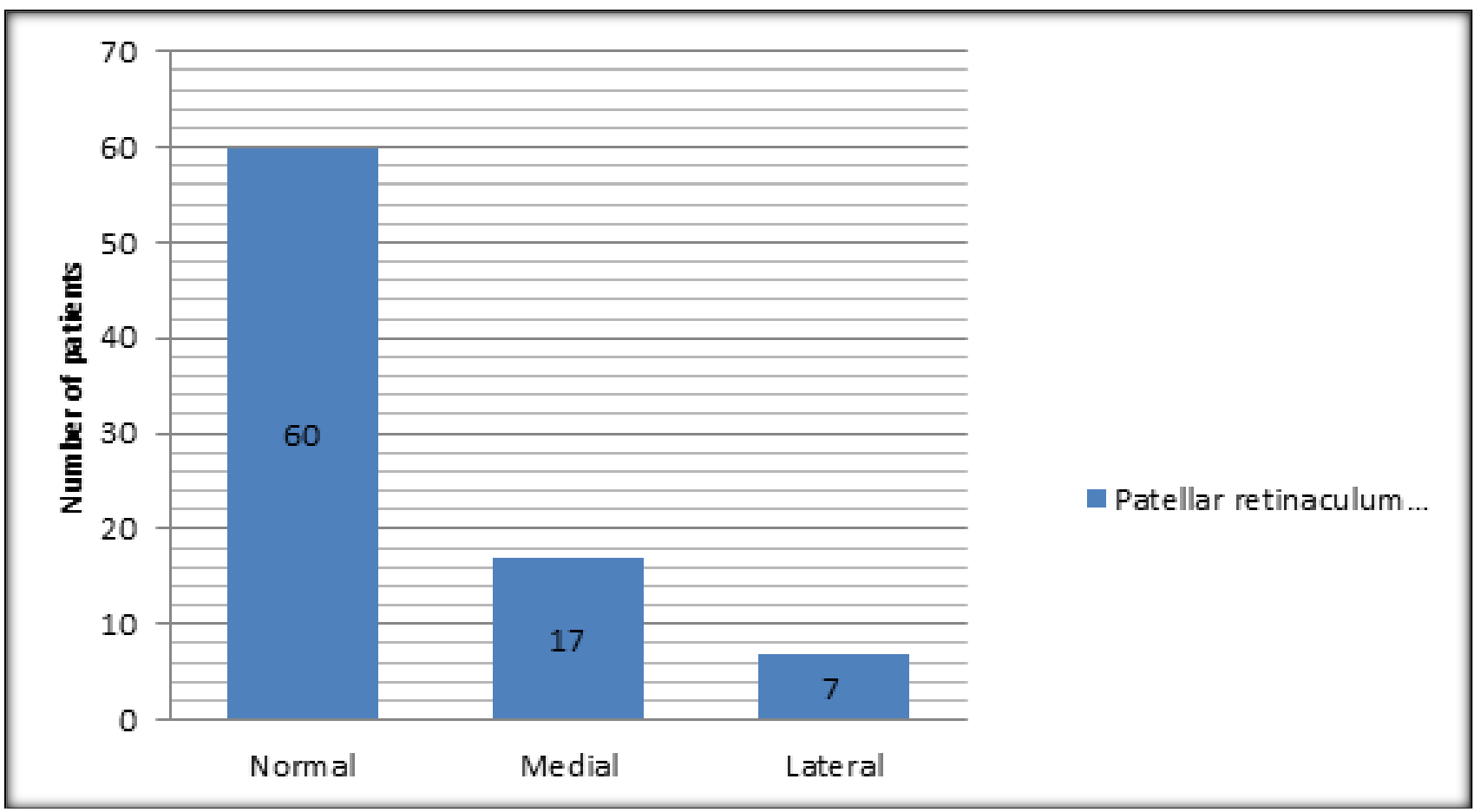

Figure 7: Number of cases with patellar retinaculum injury. 
Annals of International Medical and Dental Research E-ISSN: 2395-2822 | P-ISSN: 2395-2814

Vol-8, Issue-1 | January-February 2022

DOI: 10.53339/aimdr.2022.8.1.3

Page no- 12-23 | Section- Research Article (Radiodiagnosis)

Table 8: Spectrum of MRI findings

\begin{tabular}{|l|l|l|}
\hline Findings & Frequency & Percentage \\
\hline Joint effusion & 68 & 82.9 \\
\hline Anterior Cruciate Ligament injury & 54 & 65.8 \\
\hline Posterior Cruciate Ligament injury & 12 & 14.6 \\
\hline Medial Collateral Ligament injury & 17 & 20.7 \\
\hline Lateral Collateral Ligament injury & 5 & 6.0 \\
\hline Medial meniscal injury & 25 & 30.5 \\
\hline Lateral meniscal injury & 20 & 24.4 \\
\hline Patellar retinaculum injury & 22 & 26.8 \\
\hline Muscle oedema & 10 & 12.2 \\
\hline Tendon tear & 4 & 4.9 \\
\hline Bone marrow oedema/ contusion & 42 & 51.2 \\
\hline Fracture & 23 & 28.0 \\
\hline Cartilage injury & 6 & 7.3 \\
\hline
\end{tabular}

Table 9: Multiple ligament injuries in relation to ACL

\begin{tabular}{|l|l|l|l|l|l|l|l|l|l|l|}
\hline $\begin{array}{l}\text { ACL } \\
\text { injury } \\
\downarrow\end{array}$ & $\begin{array}{l}\text { Other } \\
\text { Ligament } \\
\text { Injuries } \\
\rightarrow\end{array}$ & MM & LM & MCL & LCL & PCL & $\begin{array}{l}\text { Patellar } \\
\text { retinaculum }\end{array}$ & $\begin{array}{l}\text { Bone } \\
\text { oedema/ } \\
\text { contusion }\end{array}$ & MCL+MM & $\begin{array}{l}\text { No other } \\
\text { ligament } \\
\text { injury }\end{array}$ \\
\hline Normal (28) & 5 & 9 & 1 & 2 & 4 & 6 & 12 & 0 & 6 \\
\hline Sprain (3) & 1 & 0 & 1 & 0 & 2 & 0 & 2 & 1 & 1 \\
\hline Tear (51) & 19 & 11 & 11 & 3 & 6 & 16 & 28 & 4 & 6 \\
\hline
\end{tabular}

Commonest finding seen on MRI was joint effusion seen in $68(82.9 \%)$ patients. ACL was the commonest ligament to show abnormality in $54(65.8 \%)$ cases. Grade 2 injury was most common $(64.8 \%)$ among them. Grade 1 and grade 3 injuries were seen in $3(5.5 \%)$ and 16 (19.5\%) cases respectively [Table 8 \& Figure 6]. PCL injury was rare accounting for only 12 $(14.6 \%)$ cases. Grade 3 tears were more common than grade $1 \& 2$.

MCL injury was seen in 17(20.7\%) cases. Grade 2 injury was most common among them seen in 12 cases. LCL injury was less common than MCL, seen in $5(6.1 \%)$ cases, all being grade 2 injury.
MM showed abnormal signal in 38 (46.3\%) out of which tears were only seen in 25 patients. Grade 1 and 2 signal were seen in 7 \& 6 cases respectively. LM abnormal signal was seen in $31(37.8 \%)$ out of which tears were seen in 20 cases. Grade 1 \& 2 signal were seen in 7 \& 4 cases respectively.

Patellar retinaculum injury was seen in 24 (26.9\%) cases. Among them MPR injury was more common than LPR injury. Muscle oedema was seen in $10(12.2 \%)$ patients and tendon tear in 4 patients out of which 3 were in quadriceps tendon and 1 was in popliteus tendon. 
Annals of International Medical and Dental Research

E-ISSN: 2395-2822 | P-ISSN: 2395-2814

Vol-8, Issue-1 | January-February 2022

DOI: $10.53339 /$ aimdr.2022.8.1.3

Page no- 12-23 | Section- Research Article (Radiodiagnosis)

Marrow oedema/contusion was most common osseous injury present in $42(51.2 \%)$ patients. Tibial intercondylar region was the most common associated fracture seen in 8 cases out of 23 patients having fractures followed by tibial plateau, femoral condyle, patella and fibula seen in 5, 4, 4 and 4 cases respectively. Cartilage injury near patellar facets was noted in 6 cases. Anterior tibial subluxation $(n=8)$ was most common followed by lateral patellar subluxation $(n=6)$ which were associated with Anterior Cruciate Ligament and Medial Patellar Retinaculum (MPR) respectively in all cases.

Out of 82 patients, most of the cases $(n=53,64.6 \%)$ had combined tears i.e. more than one ligament was torn while single tears were seen in $23(28 \%)$ cases [Table 9]. No tear was seen in $6(7.3 \%)$ patients. ACL was the most common tear seen in 51(62.2\%) patients. Out of 51, $6(11.8 \%)$ patients showed isolated ACL tear and rest of $45(88.2 \%)$ patients were associated with other ligament tears which were MM, patellar retinaculum, MCL, LM, PCL and LCL in 19 (37.2\%), 16 (31.4\%), 11 $(21.5 \%), 11(21.5 \%), 6(11.7 \%)$ and $3(5.9 \%)$ cases respectively. O'Donoghue's triad (ACL+MCL+MM tear) was seen in only 4 cases.

\section{DISCUSSION}

Imaging of knee presents a special challenge because of its complex structure. Disruption of various ligaments and cartilage around the knee joint leads to significant morbidity, especially in young adults involved with sporting activities. Therefore imaging of this complex synovial joint becomes crucial to promptly identify the pathology affecting it.
The role of magnetic resonance imaging has steadily increased and now it has become the first line investigation for most of the lesions of knee. It is also being used for pre and post operative evaluation. Complete evaluation of all the internal structures of the knee was not possible with other modalities like conventional radiography, arthrography, ultrasonography and computed tomography. Even with arthroscopy lesions such as peripheral meniscal tears, inferior surface tears and osteochondritis dessicans without articular cartilage damage are most often not detected. Multiplanar MR images provide significant improvement in assessing these structures.

Many studies have been published on sensitivity and specificity of MRI in identifying ligamentous and meniscal pathologies and imaging features compared with arthroscopy or surgical findings. These had suggested MR to be an effective tool for evaluation of knee joint.

In our study, joint effusions were the most common finding affecting 68 patients (82.9\%). Among the ligamentous and meniscal injuries, ACL tear is most common, seen in 51 patients $(62.2 \%)$ with grade 3 type injury being commonest, followed by MM injuries seen in 33 patients $(29.7 \%)$.

\section{Cruciate ligaments:}

Singh et al,[] found in their series of 173 patients, 78 patients $(45.08 \%)$ showed ACL tears, among these 52 (66.67\%), were partial, 16 (20.51\%) were complete and 10 (12.82\%) cases showed non visualization of ACL. PCL tears were seen in $10(5.7 \%)$ patients. Manoj et al,[9] in their series also showed ACL to be most 
Annals of International Medical and Dental Research

E-ISSN: 2395-2822 | P-ISSN: 2395-2814

Vol-8, Issue-1 | January-February 2022

DOI: $10.53339 /$ aimdr.2022.8.1.3

Page no- 12-23 | Section- Research Article (Radiodiagnosis)

common ligament injury seen in $35(43.75 \%)$ patients out of 80 . PCL tear was seen in 4 (5\%) patients. Sonnin et al, 10$]$ found the incidence of PCL tear to be 3 percent in a series of analyzing 350 cases of knee injury.

In accordance to above studies, our study showed most common ligament to be torn being ACL in 51 patients (62.2\%), among these $35(68.6 \%)$ were partial tears and $16(31.4 \%)$ were complete. PCL tears were uncommon, seen in only $11(13.4 \%)$ patients out of which 5 $(45.4 \%)$ and $6(54.6 \%)$ patients showed grade 2 and grade 3 injury respectively.

8 of the patients with ACL tear had associated anterior tibial subluxation which is also a seconday sign for ACL tear. Similarly one case of PCL tear had associated posterior tibial subluxation.

\section{Collateral ligaments}

In our study, MCL tears 13 (15.9\%) were found to be more common than the LCL tear 5(6.1\%). All were associated with multiple injuries except 1 case of isolated MCL and 2 cases of isolated LCL tear. This suggests presence of a single injury should prompt the examiner to look for other subtle associated injuries, which was further confirmed by Mink JH et al.[11]

In our study grade 2 tear (12 patients) of MCL were more common. The main findings in collateral ligament injuries were adjacent fascial oedema and increased signal intensity. Schweitzer et a1,12] reported grade 2 as commonest among MCL injuries and also showed higher frequency of MCL injury than ACL injury which we could not corroborate in our study. This could be because certain sports activities (skiing) have a very high incidence of
MCL injuries which are not a part of our sports culture.

\section{Meniscal injuries}

In our study out of 82 patients, Grade I signal in $7(8.5 \%)$, Grade 2 in $6(7.3 \%)$ and Grade 3 in $25(30.5 \%)$ in $\mathrm{MM}$ and Grade I signal in 7 $(8.5 \%)$, Grade 2 in $4(4.9 \%)$ and Grade 3 in 20 (24.4\%) in LM.

\section{Extensor mechanism and patellar tendon}

Tears of MPR and LPR were seen in 17 (20.7\%) and $7(8.5 \%)$ respectively. All 6 patients having lateral patellar subluxation had MPR tear. 13 and 4 patients having MPR and LPR tears respectively had associated patellar and femoral condyle oedema/ contusion. Guerrero et $a l,[13]$ showed tear of the medial patellofemoral ligament at the patellar attachment occurred in 93/195 knees (47\%), at the femoral attachment in 50/195 knees (26\%), and at both the femoral and patella attachment sites in 26/195 knees (13\%) of total 195 patients studied who had lateral patellar dislocation.

Adjacent muscle oedema was seen in 9 cases. Most of them had associated multiple injuries and history of trauma within 1 month. Partial tear of quadriceps tendon was seen in 3 cases and popliteal tendon in 1 case. These findings were correlated with findings described by Thomas H. Berquist. [14]

\section{Osseous and osteochondral lesions}

Bone marrow oedema/ contusion was the most common finding in this group seen in 42 (51.2\%) patients. On the other hand, clear distortion of the associated subchondral bone lamina (impaction) is a factor for a poor 
Annals of International Medical and Dental Research

E-ISSN: 2395-2822 | P-ISSN: 2395-2814

Vol-8, Issue-1 | January-February 2022

DOI: 10.53339/aimdr.2022.8.1.3

Page no- 12-23 | Section- Research Article (Radiodiagnosis)

prognosis with the possible development of osteoarthritis as a consequence of the irregularity of the articular surfaces.

Fractures were seen in 23 patients out of which most common was tibial intercondylar fracture seen in 8 patients. 7 patients with intercondylar fracture were associated with PCL injury. Patella fracture was associated with cartilage tear which was seen in total of 6 patients.

\section{Combined injuries}

In our study, we found 53 cases of combined injuries and 23 cases of isolated injuries. The predominant pattern is ACL tear and MM tears seen in19 cases; followed by ACL tear and LM tear in 11 cases, which does not correlated with a study by Ali Akbar Esmaili Jah et al,[15] who in a series of 70 cases got 17 concomitant injuries at MRI and arthroscopy. This can be explained by the fact that we had considered MPR \& LPR as ligament tears which they did not considered separately. O'Donoghue's triad also known as unhappy triad which is being reported as most common combined injury (ACL+MCL+MM tear) was seen in only 4 cases in our study. ${ }^{[16,17]}$ This may be due to different mechanism of injuries in our study and in other studies where sports injury is the utmost primary cause of ligament injuries in knee.

\section{Others}

Lateral Discoid meniscus with appearance of bow tie configuration in more than three

\section{REFERENCES}

1. Polly DW Jr, Callaghan JJ, Sikes RA, McCabe JM, McMahon K, Savory CG. The accuracy of selective magnetic resonance imaging compared with the contiguous slices on sagittal images was found in one patient. It has variable reported incidence between 0.4 to $16.6 \%$ by Somato et al.

Baker's cyst was seen in 5 of the total of 82 cases.

\section{CONCLUSIONS}

The present study attempts to determine the role of magnetic resonance imaging in the evaluation of internal derangements of the knee joint. Knee joint being the largest and most complex weight bearing joint of the body is subject to damage because of its inherent structural complexity and the various types forces it is subjected to.

Post-traumatic pre-arthroscopic MR imaging evaluation has proved to be cost-effective. Although arthroscopy has revolutionized the diagnosis and treatment of knee disorders, most orthopaedicians acknowledge the invasiveness of the procedure; limitations in evaluation of extra-articular pathology; cost and uncommon but potential complications associated with the procedure. They acknowledge MRI as an accurate imaging modality complementing their clinical evaluation and providing a global intraarticular and extra-articular assessment of the knee.

findings of arthroscopy of the knee. J Bone Joint Surg Am. 1988;70(2):192-8.

2. Vaz CE, Camargo OP, Santana PJ, Valezi AC. Accuracy of magnetic resonance in identifying 
Annals of International Medical and Dental Research

E-ISSN: 2395-2822 | P-ISSN: 2395-2814

Vol-8, Issue-1 | January-February 2022

DOI: 10.53339/aimdr.2022.8.1.3

Page no- 12-23 | Section- Research Article (Radiodiagnosis)

traumatic intraarticular knee lesions. Clinics (Sao Paulo). 2005;60(6):445-50.

3. Winters K, Tregonning R. Reliability of magnetic resonance imaging of the traumatic knee as determined by arthroscopy. $\mathrm{N}$ Z Med J. 2005;118(1209):U1301.

4. Oei EH, Nikken JJ, Verstijnen AC, Ginai AZ, Myriam Hunink MG. MR imaging of the menisci and cruciate ligaments: a systematic review. Radiology. 2003;226(3):837-48. doi: 10.1148/radiol.2263011892.

5. Shakoor D, Kijowski R, Guermazi A, Fritz J, Roemer FW, Jalali-Farahani S, et al. Diagnosis of Knee Meniscal Injuries by Using Three-dimensional MRI: A Systematic Review and Meta-Analysis of Diagnostic Performance. Radiology. 2019;290(2):435-445. doi: 10.1148/radiol.2018181212.

6. Saavedra MÁ, Navarro-Zarza JE, Villaseñor-Ovies $\mathrm{P}$, Canoso JJ, Vargas A, Chiapas-Gasca K, Hernández-Díaz C, Kalish RA. Clinical anatomy of the knee. Reumatol Clin. 2012 Dec-2013;8 (Suppl 2):39-45. doi: 10.1016/j.reuma.2012.10.002.

7. Li DK, Adams ME, McConkey JP. Magnetic resonance imaging of the ligaments and menisci of the knee. Radiol Clin North Am. 1986;24(2):209-27.

8. Singh J, Garg L, Shrimali R, Setia V, Gupta V. MR imaging of knee with arthroscopic correlation in twisting injuries. Indian J Radiol Imaging. 2004;14: 33-40.

9. Khan HA, Ahad H, Sharma P, Bajaj P, Hassan N, Kamal Y. Correlation between magnetic resonance imaging and arthroscopic findings in the knee joint. Trauma Mon. 2015;20(1):e18635. doi:10.5812/traumamon.18635

10. Sonin AH, Fitzgerald SW, Hoff FL, Friedman H, Bresler ME. MR imaging of the posterior cruciate ligament: normal, abnormal, and associated injury patterns. Radiographics. 1995;15(3):551-61. doi: 10.1148/radiographics.15.3.7624562.
11. Phisitkul P, James SL, Wolf BR, Amendola A. MCL injuries of the knee: current concepts review. Iowa Orthop J. 2006;26:77-90.

12. Schweitzer ME, Tran D, Deely DM, Hume EL. Medial collateral ligament injuries: evaluation of multiple signs, prevalence and location of associated bone bruises, and assessment with MR imaging. Radiology. 1995;194(3):825-9. doi: 10.1148/radiology.194.3.7862987.

13. Guerrero P, Li X, Patel K, Brown M, Busconi B. Medial patellofemoral ligament injury patterns and associated pathology in lateral patella dislocation: an MRI study. Sports Med Arthrosc Rehabil Ther Technol. 2009;1(1):17. doi: 10.1186/1758-2555-1-17.

14. Berquist TH. Osseous and myotendinous injuries about the knee. Radiol Clin North Am. 2007;45(6):955-68, vi. doi: 10.1016/j.rcl.2007.08.004.

15. Esmaili Jah AA, Keyhani S, Zarei R, Moghaddam AK. Accuracy of MRI in comparison with clinical and arthroscopic findings in ligamentous and meniscal injuries of the knee. Acta Orthop Belg. 2005;71(2):189-96.

16. Oei EH, Ginai AZ, Hunink MG. MRI for traumatic knee injury: a review. Semin Ultrasound CT MR. 2007;28(2):141-57. doi: 10.1053/j.sult.2007.01.003.

17. Staron RB, Haramati N, Feldman F, Kiernan HA, Pfaff HC, Rubin SJ, et al. O'Donoghue's triad: magnetic resonance imaging evidence. Skeletal Radiol. 1994;23(8):633-6. doi: 10.1007/BF02580384.

18. Samoto N, Kozuma M, Tokuhisa T, Kobayashi K. Diagnosis of discoid lateral meniscus of the knee on MR imaging. Magn Reson Imaging. 2002;20(1):5964. doi: 10.1016/s0730-725x(02)00473-3.

Source of Support: Nil, Conflict of Interest: None declared 